\title{
A 100-Year Review: Milestones in the development of frozen desserts ${ }^{1}$
}

\author{
R. W. Hartel, ${ }^{2}$ S. A. Rankin, and R. L. Bradley Jr. \\ Department of Food Science, University of Wisconsin-Madison, Madison 53706-1565
}

\begin{abstract}
Ice cream has come a long way since the first snow cone was made. Innovations in a variety of areas over the past century have led to the development of highly sophisticated, automated manufacturing plants that churn out pint after pint of ice cream. Significant advances in fields such as mechanical refrigeration, chilling and freezing technologies, cleaning and sanitation, packaging, and ingredient functionality have shaped the industry. Advances in our understanding of the science of ice cream, particularly related to understanding the complex structures that need to be controlled to create a desirable product, have also enhanced product quality and shelf stability. Although significant advances have been made, there remain numerous opportunities for further advancement both scientifically and technologically.
\end{abstract}

Key words: ice cream, frozen dessert, microstructure, processing

\section{INTRODUCTION}

Frozen desserts developed over history in much the same way as most foods: our ancestors kept trying different things until they found something that worked. Although numerous origin stories exist, the first frozen desserts likely were made by flavoring snow or ice. This may have been intentional but may also have simply occurred by chance. It is not our intention to delve into truth or myth because the history of frozen desserts has been documented in numerous publications (e.g., Quinzio, 2009).

An enormous industry has grown up around standardized commercial products. Many of the advances in the ice cream industry have been driven by technological inventions. For example, improved methods of refrigeration, from ice harvesting to mechanical refrigeration, have significantly influenced the development of ice cream over the past century. Although chefs and

Received June 2, 2017.

Accepted July 16, 2017.

${ }^{1}$ This review is part of a special issue of the Journal of Dairy Science commissioned to celebrate 100 years of publishing (1917-2017).

${ }^{2}$ Corresponding author: rwhartel@wisc.edu entrepreneurs continually explore new frozen dessert ideas, as with many other foods, the development of high-quality products proceeded without much, if any, scientific understanding. In the past century, scientists have attempted to bring a better scientific understanding to such foods. We continue to conduct experiments on ice cream to better understand the scientific basis for this long-cherished treat in hopes of providing new and unique ways to deliver consumer satisfaction. In this review, we highlight advances and developments in ice cream and frozen desserts over the past century, with a focus on how the Journal of Dairy Science has played a role in that development. As the premier dairy journal, many of the important advances in the development of ice cream have unfolded in its pages over the past century (see Appendix Table A1).

\section{INGREDIENTS}

Some hundred years ago, little consideration was given to the individual or collective contributions of the components of ice cream mix as they related to the actual structure-function relationships of finished ice cream products. Historically, milk, cream, and sugar were the fundamental ingredients of ice cream in its most rudimentary form. Flavored, frozen, and whipped into a popular dessert, there was little need to improve this successful formulation. However, as market pressures and economic opportunities arose, ice cream needed to change in many ways, including exhibiting stability over long-term frozen storage and responding to a more diverse population interested in issues such as changes in nutrient content. The gap between the readily manufactured, well-recognized version of ice cream as a conventional dessert and the need for ice cream to change to meet market demands spawned the ensuing century of research focused on bridging the significant knowledge gap of the scientific underpinnings of ice cream - arguably one of the most complex foods manufactured. Such complexity is manifest in several ways that to this day defy complete characterization. For instance, consider that ice creams contain or display multiple physical states and forms (including liquid, solid, and gas phases) and significant foam structure, solvent-solution interactions, and varying permuta- 
tions on emulsion structure. Collectively, these forms exhibit a diverse collection of physical and sensory attributes over a large temperature range. For example, ice cream mix must be sufficiently liquid at pasteurization treatment to flow through various heat exchangers at over $80^{\circ} \mathrm{C}$, then be sufficiently malleable as a frozen foam to allow scooping or serving to occur at approximately $-15^{\circ} \mathrm{C}$, then remain rigid and stable to meet a long-term storage convention of 1 yr under freezing temperatures of $-30^{\circ} \mathrm{C}$. Add to this list a host of other critical factors that must be achieved, such as the bearing of an ever-increasing collection of inclusions and variegates and the ability to appropriately melt upon consumption and to provide a "comfort food" level of satiety and enjoyment to the imbiber. These and other attributes are achieved through specific processing and freezing parameters and by the deliberate addition or manipulation of various ingredients that are critical to the character of ice cream based on our knowledge of structure-function relationships involving dairy ingredients, sweeteners, stabilizers, emulsifiers, and a growing collection of other critical ingredients designed to meet the shifting demands on ice cream or related frozen dessert products. From quintessential backyard summer dessert to engaging the greatest minds in dairy foods science, the list of functional roles of ice cream ingredients can be described as either short and simple or long and complicated depending on the application and audience. Discoveries of the finer chemical and physical roles of ice cream ingredients have been the subject of routine research activities over the past century and are presented in this article.

\section{Dairy-Based Ingredients}

Given all of the potential states that dairy ingredients and components can take and the flexibility provided through mix standardizing technologies and compositional requirements, few dairy-based ingredients have not found their way into ice creams for a variety of functional, nutritional, and economic purposes. The dairy ingredient components - namely $\mathrm{CN}$ and whey proteins, milk fat, lactose, and mineral salts - each play roles of varying degrees of importance.

Because of the complex and heterogeneous nature of $\mathrm{CN}$ proteins and the native state of those proteins present in micellar form, the $\mathrm{CN}$ proteins and their derivatives have played numerous roles in frozen dessert characteristics (Goff et al., 1989; Chang et al., 1995; Alvarez et al., 2005). Whey and its derivatives have also been the source of investigations aimed at exploiting the unique properties of whey components and the known chemical or physical phenomena present in frozen desserts (Prindiville et al., 2000; Levin et al., 2016).
An increased understanding of the role of milk proteins should parallel the degree to which high protein intake remains an important consumer interest (see Patel et al., 2006).

Milk fat plays many significant roles, including nutritional roles (e.g., caloric density, lipid-soluble vitamins), in the characteristics of frozen desserts. Milk fat is a solvent for flavors such as vanilla ( $\mathrm{Li}$ et al., 1997) and affects the sensory and rheological properties of ice cream based on the physical forms that the milk fat assumes during the manufacturing processes (Kalab, 1985; Goff, 1997). The effects of freezing (Doan and Baldwin, 1936) and shear forces destabilize the relatively distinct dispersion of milk fat globules coated with an interfacial complex (referred to as the milk fat globule membrane) and result in the formation of aggregated, structure-imparting milk fat globule clusters typically referred to as full or partial coalescence (Goff, 1997) and flocculation, depending on the aggregate mechanism (Méndez-Velasco and Goff, 2012). The final connections between these mechanisms, their resulting milk fat-based structures, and the final rheological and sensory properties of the final product (Warren and Hartel, 2014) remain topics of interest, especially in frozen desserts that have novel compositions. There is continual interest in pursuing an improved understanding of the roles that milk fat plays in ice cream as a function of temperature, shear force, and the unique chemistries of novel frozen dessert mixes (e.g., the presence of surfactant molecules).

The presence of lactose in ice creams has been the source of various research activities. In general, the level of lactose in ice cream can be quite high, nearing $8 \%$, resulting in concerns for those who experience lactose malabsorption issues. High lactose content is, in part, a function of the US standards of identity requiring that milk be fortified with milk fat and milk SNF above what is natively found in milk and the availability of lactose-rich ingredients designed to serve that purpose. These high lactose levels play a significant role in the overall freezing point depression of the serum phase of ice cream (Goff and Hartel, 2013) and contribute to a small degree to the overall sweetness of the frozen dessert. Excessive levels of lactose and abusive storage conditions can render lactose insoluble, resulting in the crystallization of lactose molecules and the concomitant sensory defect known as sandiness (Nickerson, 1954). Interest in reducing lactose and overall carbohydrate content in ice creams has been a current focus of inquiry, as has the inclusion of lactose derivatives such as polymerized lactose with reported prebiotic function (Tremaine et al., 2014; Balthazar et al., 2015).

Given that ice creams are, in essence, concentrated milk components, the mineral density-more specifi- 
cally, the calcium and phosphorus content - can arguably have a significant positive effect on the nutritional contribution of frozen desserts (Auld et al., 2002). Also, because ice cream structure is in part a function of ionic bonds present, changes to the presence or availability of especially polyvalent ionic minerals have been shown to produce unique, sometimes unanticipated effects in even some very early experiments (Hening, 1929). Calcium fortification based on increasing nutrient content was shown to increase ice crystal growth through effecting decreases in the $\mathrm{CN}$ micelle size and increased milk fat destabilization in frozen desserts with added к-carrageenan stabilizer (Costa et al., 2008).

\section{Hydrocolloid Stabilizers}

A wide variety of hydrocolloid chemistry studies have examined the physical and chemical properties and behavior of typically larger molecules or particles dispersed within or residing at the interface of an aqueous continuous phase. Ice cream has transitioned from a product historically consumed soon after manufacturing to a product currently designed to maintain desirable sensory properties over an extended storage period, and interest in building richness-imparting viscosity has increased. Therefore, the inclusion of hydrocolloid stabilizer systems has been routine in the design of ice cream mix. Such hydrocolloids are typically carbohydrate in nature but may contain protein-based ingredients, such as gelatin (Wright, 1930; Leighton et al., 1934; MillerLivney and Hartel, 1997). The chemical and physical actions of the hydrocolloids involve mechanisms based on various factors, including the presence of charged moieties, hydrophobic regions, and high water-holding capacities of such ingredients (Schmidt and Smith, 1992). Advances in this realm have led to the inclusion of a vast array of stabilizers derived from a variety of sources (Caulfield and Martin, 1933; Regand and Goff, 2002; Javidi et al., 2016) that affect the rheological, stability, and sensory properties. In general, these stabilizers impede the outgrowth of ice crystals and the sublimation of water (Dubey and White, 1997) while increasing the viscosity of the mix, sensory smoothness, and foam stability (Goff and Hartel, 2013).

\section{Emulsifying Agents}

Many ingredients of ice cream, including some proteins and lipids, exhibit the ability to influence the physics of the interfacial or emulsion-like molecules between the aqueous and bulk lipid phases of frozen desserts. Because the structure of finished frozen dessert products may be influenced by the state of these chemistries, measures have been taken to include or optimize ingredients to increase the presence or efficacy of surfactant capacities. Historically, whole eggs or egg yolks were added as a means of improving various sensory properties of frozen desserts (Mueller and Button, 1929). More recent work has led to the evaluation and inclusion of a collection of emulsifying agents such as polysorbate compounds, native phospholipid concentrates, and triglyceride derivatives (Baer et al., 1999; Daw and Hartel, 2015). A general mechanism for emulsifier behavior resides in the ability to reduce interfacial tension of the milk fat globule interface, making it further susceptible to the destabilization or coalescence phenomena during the manufacturing process.

\section{Sweeteners}

Despite the relatively familiar character of food sweeteners common to frozen desserts (e.g., sucrose), their roles and chemistries are varied and diverse. Aside from imparting the sensory attribute of sweetness, these ingredients influence a wide variety of other characteristics such as freezing point depression, solution osmotic strength, ice crystal growth, reactivity (e.g., with primary amines), and product rheology or malleability. Early studies, primarily driven by economic interests, explored sucrose replacement using ingredients such as invert sugar and corn starch-based sweeteners (Frandsen et al., 1919). The discovery of high-intensity sweeteners and the interest in reduced-carbohydrate diets have driven an interest in the inclusion of nonnutritive sweeteners such as aspartame and sucralose (Specter and Setser, 1994). However, with this interest comes sensory and functional concerns given the multivalent role of traditional carbohydrate sweeteners in frozen desserts (Cadena et al., 2012), most notably the dramatic reduction in solute concentration needed for freezing point depression.

\section{Flavorants, Colorants, Variegates, and Inclusion Additives}

There seems to be few limitations on the number and variety of flavor-, texture-, and color-imparting additives that find their way into frozen desserts. Ethnic and regional influences help create interest in diverse flavor options, and few flavors - including those of a savory nature - have not been successfully marketed or at least attempted in a frozen dessert form. Apart from flavor intensity and compatibility, this presents various topics of scientific interest. First, not all of these additives can be seamlessly presented in frozen desserts. For instance, chocolate products served at frozen dessert temperatures are typically modified to exhibit improved meltability and flavor character (Cebula and 
Hoddle, 2009). Perhaps more significant is that the vast majority of these additives are added after the pasteurization process, thus placing significant demands on food safety practices during the manufacturing and handling processes. Ice cream has also been susceptible to food safety concerns (Buchanan et al., 2017).

\section{Novel Ingredients}

There certainly are ingredients that have critical roles in modern frozen desserts that are not included in the categories above. Compared with the simple product of the past, modern frozen desserts are available in an assortment of compositional variants, such as "no sugar added" products or those with little or reduced milk fat content. As noted previously, the fundamental ingredients in frozen desserts such as sugar and milk fat serve a vast array of functional purposes and cannot simply be replaced without some degree of design to yield a product that has the sensory and functional properties of the original (Guinard et al., 1997). For instance, the manufacture of no sugar added products has been a significant area of development for those seeking to reduce calories by reducing carbohydrate intake. No sugar added ice creams typically still contain sugars native to the milk ingredients (namely lactose) but replace the sucrose or carbohydrate sweetener with a high-intensity sweetener such as aspartame. Although the sweetness may approach that of the native product, the absence of sucrose yields a product with such a high freezing point that it is incompatible with the critical freezing systems involved in the manufacture and serving of ice cream. In response, small molecular weight sugar alcohols with lower glycemic indices (e.g., maltitol, sorbitol, or erythritol) are added as a means of obtaining desirable freezing point depression (Moriano and Alamprese, 2017).

The replication by novel ingredients of attributes imparted by milk fat seems to have presented a more complicated task. In addition to imparting nutritional and flavor-related qualities, milk fat imparts significant structural and textural characteristics that change over the course of consumption in a unique but anticipated manner. The changes in texture involve changes in the physical structure that milk fat has assumed in frozen desserts as well as changes in physical state (i.e., solid to liquid) as the product is consumed. Finding a single ingredient that is capable of producing these unique attributes has been challenging. Thus, most approaches involve the inclusion of multiple ingredients, including hydrocolloids (Akbari et al., 2016), proteins (Akalın et al., 2008), and corn derivatives (Roland et al., 1999). However, studies suggest that much work is still re- quired to gain a fundamental understanding of the role of milk fat in frozen desserts as well as the design and selection of ingredients that are capable of successfully replacing milk fat.

\section{FREEZING, PACKAGING, AND HARDENING}

From the early days, ice cream manufacturers have continually sought methods to improve both product quality and manufacturing efficiency. Advances in frozen dessert technology in general have taken advantage of advances in dairy processing. For example, separation, pasteurization, and homogenization techniques have advanced significantly over the past century, improving the process of making all dairy foods, including frozen desserts. Because these dairy processing techniques are discussed elsewhere, the focus here is on processes unique to ice cream.

\section{Freezing}

Ice cream is distinguished from other dairy products by the freezing operation. Thus, advances in ice cream production have generally followed advances in refrigeration processes. Although mechanical refrigeration was first developed in 1878, even for many decades thereafter ice cream was frozen using a brine (rock salt and ice) system as a heat transfer medium. This posed problems for ice cream makers because brine temperatures are limited to $-5^{\circ} \mathrm{F}\left(-23^{\circ} \mathrm{C}\right)$, so freezing rates and ice cream quality did not meet current standards. In the early 1900s, horizontal circulating brine freezers were introduced that greatly enhanced production rates and control of ice cream making, although maintaining low brine temperatures was still problematic. The first direct-expansion ice cream freezer was invented in 1913 (Goff and Hartel, 2013), but it was still many years before such freezers became extensively used; the first commercially adopted continuous freezer was seen in 1926 (Goff and Hartel, 2013). Fisk (1919) mentioned the use of mechanical refrigeration but noted that brine freezing was still most common at that time. Even in 1932, brine freezers were still widely used. Sommer (1932) stated, "Brine freezers are still most common, but direct expansion freezers have been perfected and being quite generally used." Brine freezers were quickly phased out after that, giving way to the enhanced control and production of direct-expansion, mechanical-refrigeration ice cream freezers.

Mechanical refrigeration became widespread in the 1930s with the advance of home refrigerators and freezers as well as commercial frozen storage units. This 
allowed high-quality ice cream to reach consumers for in-home consumption. Numerous advances in storage freezer technology have continued in recent years, with efforts, for example, aimed at reducing environmental pollution (e.g., restrictions on fluorocarbons) and energy costs (e.g., phase change panels within storage freezers).

In terms of ice cream freezer design, numerous advances have occurred in the past $100 \mathrm{yr}$, although few of those developments were recorded in the Journal of Dairy Science because of the engineering basis of equipment development. One early article, however, compares cleaning and sanitizing protocols based on hot water, steam, and chlorine (Fabian et al., 1942).

The basic direct-expansion ice cream freezer has changed significantly in the past half century. Modern freezers have been designed to improve consistency and maximize throughput and efficiency by minimizing energy use and product losses. Programmable controls also enhance efficient operation and reduce labor requirements.

Several major advances in ice cream freezer technology based on the development and application of extruders are noteworthy. For one, extrusion technology for creating novelty products grew significantly in the 1980s (Goff and Hartel, 2013). Another major development in freezer technology overlaps with the low-temperature extrusion process for ice cream manufacture developed in the 1990s (Wildmoser and Windhab, 2001). Here, the product from the draw of a standard scraped surface freezer is cooled further in an extruder that operates with low rotational speed. This slow churning process helps maintain small ice crystals and air bubbles by rapidly freezing to low temperatures $\left(-12\right.$ to $\left.-15^{\circ} \mathrm{C}\right)$, creating a product with a smoother texture.

\section{Packaging}

In 1919, ice cream from the brine freezer was quickly unloaded into metal packing cans (Fisk, 1919). These cans were made of heavy iron in sizes from $0.9 \mathrm{~L}$ (1 quart) to $18.9 \mathrm{~L}$ (5 gallons). From these packing tins, the ice cream was packed into brick molds, from which smaller bricks were cut and stored in parchment paper for sale. Filling and packaging technology advanced quickly in subsequent decades. Sommer (1932) included a photo of an automatic packing can filler and described its operation, in which ice cream was fed from a batch freezer into a hopper for can filling. These units were beneficial when at least 6 freezers were feeding the system, but there was a loss of quality because some melting of product occurred during handling and filling, primarily resulting in ice cream with larger detectable ice crystals. A loss of overrun of up to $10 \%$ also resulted from handling ice cream during packaging (Sommer, 1932).

Automated filling and packaging machines brought changes to the package itself. For many years, the standard ice cream package was made of wax-coated cardboard in the form of half-gallon bricks. These rectangular boxes gave way to round or oval containers to facilitate consumer scooping, among other reasons. Round, conical, or square-round containers have now mostly replaced the half-gallon brick packaging.

Modern ice cream fillers are extremely sophisticated and are sequenced to accept the output of continuous freezers and fill containers of all sizes (Goff and Hartel, 2013). Little to no melting of ice cream occurs. Package sizes vary from $100 \mathrm{~mL}$ to $8 \mathrm{~L}$ for consumers and up to $24 \mathrm{~L}$ for tubs of bulk ice cream, and packages are primarily made of paperboard or plastic material. Large-scale bulk fillers can fill 24-L tubs at a rate of up to 480 units/h (Goff and Hartel, 2013).

\section{Hardening}

In the early years of the commercial industry, ice cream was hardened with rock salt and ice in slush boxes (Fisk, 1919). As mechanical refrigeration systems became more common, larger plants adopted them for all applications (Sommer, 1932). Tracy and McCown (1934) summarized some of the most important factors that influenced hardening of ice cream, including freezer temperature, air velocity, and container size, all of which are still appropriate to consider today.

Modern hardening rooms are much more efficient than those available in the early 1900s, with extremely rapid cooling providing a higher quality product by maintaining reduced ice crystal size. The development of spiral conveyor designs allowed for more efficient use of manufacturing plant space compared with linear tunnels. The goal of a hardening room should be to achieve a core temperature of $-18^{\circ} \mathrm{C}$ within $4 \mathrm{~h}$. Rapid hardening prevents recrystallization of ice crystals and growth of air cells while the product is still relatively warm $\left(-12\right.$ to $-6^{\circ} \mathrm{C}$; Goff and Hartel, 2013). However, rapid hardening is still limited by heat transfer through the surface of the package, setting up a thermal gradient in which the product at the center remains warm for a longer time. During this time, recrystallization causes an increase in ice crystal size (Donhowe, 1993) and disproportionation causes an increase in air cell size (Chang and Hartel, 2002c). The low-temperature extrusion process is a form of extremely rapid hardening, ensuring that the entire product mass is cooled uniformly and rapidly to low temperatures (Wildmoser and Windhab, 2001). 


\section{ICE CREAM MICROSTRUCTURE}

A unique multiphase food product, ice cream is a foam, a dispersion of ice crystals, and an emulsion with fat globules that may be partially destabilized. These elements are held together by a serum phase that contains dissolved sugars, salts, and proteins as well as micellar CN (Kalab, 1985; Berger, 1990; Goff, 1997; Goff and Hartel, 2013). Depending on the hydrocolloid stabilizer used, there may also be a weak gel formed through the serum phase. Each of these structures plays an important role in determining the quality and shelf life of ice cream.

Studies of these different ice cream structural elements have increased over the past century, and significant advances have been published in the Journal of Dairy Science. In particular, advances in microscopic evaluation of the different components have improved our understanding of the complex multiphase structure of ice cream. Cole (1932a) published an early article on using optical microscopy to study ice cream texture, which was quickly followed by a modified method published by Fay (1933). Keller et al. (1943) expanded that to the use of polarized light microscopy. Arbuckle (1960) described an optical microscopy technique for characterizing cream structure. The use of scanning electron microscopy images of dairy products began in the early 1970s (Kalab, 2010). Buchheim and Knoop (1970) and Berger et al. (1972a, b) appear to be the first to publish scanning electron microscopy images of ice cream. Berger (1990) reviewed ice cream structural analyses in significant detail. These and other such publications (e.g., Donhowe et al., 1991; Caldwell et al., 1992a, b; Chang and Hartel, 2002a) helped advance our understanding of ice cream microstructure over the past century. One notable advance in microstructure analysis in recent years is the use of X-ray tomography to characterize in situ 3-dimensional structure (Pinzer et al., 2012).

The effects of microstructure on quality and texture also have been studied over the years. Some early work focused on the effects of different ingredients and processing methods on ice cream viscosity (Leighton et al., 1934). Cole and Boulware (1940) looked at the effects that mix composition had on the texture of ice cream, although not through an analysis of structural elements. Shama and Sherman (1966) used a mechanical model approach to correlate rheological properties of ice cream with microstructural elements. Muse and Hartel (2004) correlated ice cream microstructure with melting rate and hardness. Koxholt et al. (2001) found that fat globules or clusters above a critical size significantly inhibited meltdown of ice cream, although Warren and Hartel (2014), studying commercial ice creams, found that the correlation between meltdown and fat globule or cluster size distribution was confounded by other factors as well. Wildmoser et al. (2004) correlated microstructure on rheological properties and quality of ice cream. Research continues on how the structural elements in ice cream influence quality and shelf life.

\section{Ice Phase}

The ice phase provides an eating experience that is unique to ice cream. The numerous small ice crystals provide a cooling effect while also yielding a smooth, creamy mouthfeel. Controlling both the amount of ice and the nature of the ice crystal dispersion (mean size, range of sizes) is one of the most important factors in creating a desirable product. Unacceptable changes in ice crystal dispersion, or coarsening, can signal the end point for shelf life. Because the total amount of ice formed (assuming equilibrium) is found from a serum phase mass balance through the freezing point depression curve (see the Serum Phase section), the focus here is on the dispersed phase characteristics, namely mean size and size distribution.

As noted previously, studies investigating the structural aspects of ice cream were already underway by the early 1930s. By the 1960s, microscopic examination of ice crystals in ice cream was already well advanced (Arbuckle, 1960), but advances in scanning electron microscopy truly enhanced our understanding of ice cream structures, including ice crystals (Berger et al., 1972a, b). Berger (1990) cited 3 earlier references to ice crystal size, quoting as small as $20 \mu \mathrm{m}$ and as large as $56 \mu \mathrm{m}$. Donhowe et al. (1991) then published a method for quantifying the entire ice crystal size distribution in ice cream based on image analysis of samples observed through a microscope housed in a refrigerated glove box system. Their results showed that the ice crystal size distribution fit best to a log normal distribution, exhibiting a skew to larger sizes. Warren and Hartel (2014) used the method of Donhowe et al. (1991) to evaluate structural attributes of a range of commercial ice creams purchased from the local supermarket and documented a range of ice crystal sizes from as small as $26.3 \mu \mathrm{m}$ to as large as $67.1 \mu \mathrm{m}$ (mean $=48.1 \mu \mathrm{m})$.

Despite its importance in modern ice cream manufacture, the scraped surface freezer has received very little quantitative study. Russell et al. (1999) and Drewett and Hartel (2007) studied ice crystal formation in the scraped surface freezer and found that residence time within the freezer had a major effect on final ice crystal size exiting the freezer. Both studies show that longer residence times allow a greater extent of ripening, where large crystals within the bulk grow at the expense of small dendritic nuclei generated by scrap- 
ing the cold wall, resulting in larger ice crystals at the exit of the freezer. Cook and Hartel (2011) investigated the breakup of the small dendritic ice crystals as they were scraped off the barrel wall and mixed with warmer product in the center of the barrel. Cook and Hartel (2010) reviewed current knowledge on freezing processes for the scraped surface freezer.

The effects of both ingredient formulation and processing conditions on the ice crystal distribution have been studied widely over the years. Donhowe et al. (1991), for example, studied changes in ice crystal size distribution during processing. For an ice cream made from a mix with $40 \%$ TS, mean crystal size immediately out of the freezer was less than $30 \mu \mathrm{m}$, whereas after hardening the mean size had grown to about 35 $\mu \mathrm{m}$ based on the increase in ice phase volume at the lower temperature. They also documented that mean ice crystal size increased with a decrease in TS content (from $40 \%$ down to $31 \%$ ), most likely because the phase volume of ice was higher in mixes with lower TS content.

One of the major shelf life issues of ice cream is ice recrystallization, where ice crystals gradually grow larger over time based on thermodynamic ripening principles, leading to a coarse ice cream texture. Numerous studies have investigated ice recrystallization during storage; the results are summarized in a review by Hartel (1998). In particular, stabilizers are added to help control ice recrystallization. Numerous studies over the years have attempted to better understand how and when stabilizers work (Harper and Shoemaker, 1983; Hagiwara and Hartel, 1996; Miller-Livney and Hartel, 1997; Flores and Goff, 1999a, b; Trgo et al., 1999; Bolliger et al., 2000). More recently, the effects of ice structuring proteins on recrystallization in ice cream have been investigated (Regand and Goff, 2006).

\section{Air Phase}

According to the US standard of identity for ice cream, the maximum amount of air that can be incorporated is $50 \%$ relative to the volume of mix (e.g., where $2 \mathrm{~L}$ of ice cream is made from $1 \mathrm{~L}$ of mix). Overrun was also called "swell" in the early years of ice cream making (Fisk, 1919). A recent commercial survey of US ice creams showed that overrun ranged from 21.7 to $119 \%$, with a mean of $75 \%$. In general, higher overrun products had lower fat content than superpremium ice creams with $14 \%$ or higher fat content (Warren and Hartel, 2014). Air provides unique texture to ice cream, reducing the density and increasing scoopability. Both the amount of air and its distribution are important.
Also, changes during storage can influence ice cream texture and contribute to the end of shelf life.

In the early days of ice cream studies, attention was focused on the effects of mix composition and process parameters on aeration capabilities of the mix (Sommer, 1932). It was not until many years later that methods of visualizing and quantifying air cells reached the point of providing useful information. The optical microscope methods noted previously generally have not been valuable for quantifying air cells because the nature of the sample preparation generally destroys the air cells. This means that scanning electron microscopy has been the main approach (Berger et al., 1972a, b). Berger (1990) cites several references that suggest that air cell sizes are quite large (i.e., over $100 \mu \mathrm{m}$ in size) in contrast to the modern understanding that air cells are generally around $20 \mu \mathrm{m}$ in size (Goff and Hartel, 2013). The differences could be caused by differences in air incorporation in modern ice cream freezers. Chang and Hartel (2002a) developed an optical microscopy method for quantifying the complete air cell size distribution that matched well with scanning electron microscopy quantification. Their results clearly show that mean air cell size in ice cream is closer to $20 \mu \mathrm{m}$. They then used the method to document how air cells develop and are broken down in a batch freezer (Chang and Hartel, 2002b) and how they change during storage (Chang and Hartel, 2002c). Warren and Hartel (2014) used the same method to show that the mean air cell size in commercial products in the United States varied from as small as $17.1 \mu \mathrm{m}$ to as large as $39.5 \mu \mathrm{m}$ (mean $=29.9 \mu \mathrm{m})$.

Shrinkage of ice cream during storage can be a problem, particularly when packages are transported under conditions where pressure changes, as in transport over mountains. The decrease in pressure as elevation increases causes an increase in air cell volume based on the ideal gas law. When atmospheric pressure returns to normal (i.e., at sea level), the air cells shrink back, which, depending on the elastic nature of the components stabilizing the air cells, can cause the entire product to shrink away from the package. In extreme cases, a product can lose substantial volume, leading to consumer complaints. Nickerson and Tarussek (1955) provided guidance to manufacturers of the day on how to control shrinkage. More recently, Dubey and White (1997) reviewed past publications on shrinkage of ice cream and discussed potential mechanisms. Factors that potentially decreased shrinkage included addition of corn syrup, use of higher pasteurization temperatures, proper aging of mix, use of whey proteins, and use of stabilizers and emulsifiers. 


\section{Fat Phase}

According to the US standard of identity, ice cream must contain a minimum of $10 \%$ milk fat, whereas premium and superpremium ice creams may have upward of $16 \%$ fat. The fat globules are typically on the order of $1 \mu \mathrm{m}$ or so in diameter following pasteurization and homogenization and are well stabilized by milk proteins. Upon cooling and during aging, a portion of the fat crystallizes to produce partially crystalline fat globules (Adleman and Hartel, 2001) with more or less stability depending on the amount and type of emulsifier added. It is well known that the addition of emulsifiers (particularly polysorbate 80 ) to ice cream mix causes desorption of protein from the fat globule surface, reducing the stability of the emulsion droplets (Goff and Hartel, 2013). In the case of ice cream, emulsifiers are added to destabilize the emulsion. This allows individual fat globules to partially coalesce during the intense shear forces in freezing to form aggregated clusters of fat globules that provide unique structural attributes in ice cream. In particular, these fat globule clusters provide a generally desirable measure of resistance to melt down. However, if excessive fat destabilization occurs due to either high shear forces or high fat content, churning of the emulsion results, leading to visible butter granules. Among commercial ice cream samples, fat destabilization varied from 2.6 to $55.3 \%$, with a mean level of 21.9\% (Warren and Hartel, 2014).

The phenomenon of partial coalescence has been widely studied over the years, with the first specific mention of fat destabilization in the Journal of Dairy Science credited to Mahdi and Bradley (1969), although earlier work (Keeney, 1958; Keeney and Josephson, 1958; Kloser and Keeney, 1959) had already developed the colloidal approach to the fat phase. Tong et al. (1984) studied fat destabilization in frozen desserts made with safflower oil replacing some of the milk fat. Goff and Jordan (1989), Goff et al. (1989), Pelan et al. (1997), and Zhang and Goff (2005), among others, have studied the effects of emulsifiers and proteins on fat destabilization.

One of the earliest (and still best) images of partially coalesced fat globules is found in a review of the microstructure of fat-based dairy products by Kalab (1985). A transmission electron microscope image clearly shows 6 different fat globules fused together with liquid fat bridging the partially crystalline individual globules. Walstra (2003) postulated that partial coalescence was initiated by a fat crystal from one globule extending out of the surface and penetrating the interface of a neighboring globule, causing sharing of liquid fat. However, recent work by Thiel et al. (2016) clearly shows that partial coalescence occurs without the necessity of crystalline protuberances. Under the proper conditions, the interfaces of 2 fat globules begin to relax toward coalescence, based on the reduction of surface energy, but the crystalline rigidity within the globules arrests coalescence before it is completed.

Fat globule clusters have an important role in texture and sensory properties of ice cream. In particular, larger clusters are known to influence the meltdown rate of ice cream (Koxholt et al., 2001), although other factors influence meltdown rate as well (Warren and Hartel, 2014). Fat also plays an important role in the sensory attributes of ice cream, including flavor release. Hyvönen et al. (2003) showed that the temporal sensory properties of ice cream were significantly reduced in a nonfat product, although fat content and type had much less effect.

\section{Serum Phase}

An understanding of the liquid, or serum, phase in ice cream is just as important to controlling quality as an understanding of the dispersed phases. The serum forms the lamellae that surround the air cells in frozen products. Keeney and Maga (1965) collected a foam fraction that made up the lamella and analyzed its composition. Not surprisingly, it was found to be concentrated in fat and protein along with other serum components, but the specific composition seemed to depend on the nature of the emulsifiers used.

The freezing point depression of the serum phase determines the freeze concentration effect, so it is a critical aspect to control. Mixes with high freezing point temperature have more ice frozen and are harder at any storage temperature than mixes with lower freezing point temperature. This was understood already in 1925 when Parfitt and Taylor (1925) quantified the effects of mix ingredients on freezing point. Leighton (1927) then published calculated values of freezing point depression based on mix composition and estimated the amount of ice formed at each temperature, assuming that the ice content had reached phase volume equilibrium with the serum. Cole (1932b) also calculated the increasing concentration of mix components (e.g., proteins, sugars) during freezing. Bradley (1984) plotted freezing curves for dairy desserts, clearly documenting how much ice forms at any temperature, again assuming ice phase volume equilibrium. Details of freezing point calculations and freezing curves are covered in Goff and Hartel (2013).

Freeze concentration causes significant changes in the serum phase. In particular, there is an increase in viscosity, but entanglement of the stabilizers also 
undoubtedly plays a role in stability of ice cream in storage (Goff et al., 1993). This increasing viscosity of the serum phase as temperature decreases eventually leads to the glass transition at temperatures of -32 to $-40^{\circ} \mathrm{C}$ (Levine and Slade, 1988). Although the concept of glass transition as applied to foods is largely attributed to Levine and Slade (1986), the concept of ice cream as a glass under very low storage temperatures was already understood by Sommer (1932). Levine and Slade further expounded on the concept in subsequent publications (Levine and Slade, 1988; Levine and Slade, 1992), even developing frozen desserts that were significantly more stable during storage based on the stability inherent with the glassy state. Goff et al. (1993) showed that polysaccharides did not affect the glass transition temperature of ice cream mix but most likely influenced the nature of the freeze-concentrated serum in frozen ice cream, particularly at low storage temperatures. Whelan et al. (2008) evaluated the effects of trehalose as a sucrose replacement for sucrose, finding that trehalose increased the glass transition temperature slightly. However, this difference did not lead to significant decreases in ice recrystallization rates.

The concentration effect on hydrocolloids and proteins also has important effects on ice cream quality. The incompatibility of hydrocolloids with proteins causes phase separation of the serum phase (Regand and Goff, 2002), which can influence meltdown rates, sensory properties, and stability against heat shock (Regand and Goff, 2003).

Another effect of freeze concentration of the serum phase is the supersaturation of lactose. Under certain circumstances, lactose is likely to crystallize from the serum phase during storage (Whitaker, 1933). In fact, the article by Williams and Peter (1930) may be the first identification of the sandiness defect being related to lactose. However, it was Nickerson who published a sequence of seminal articles in the Journal of Dairy Science in the 1950s and 1960s that truly identified and confirmed the problem and provided potential solutions (Nickerson, 1954, 1956, 1957, 1962). Thanks in large part to Nickerson's work, the sandiness defect has been reduced to only sporadic events.

\section{FUTURE CHALLENGES}

Although food scientists have made significant progress over the past $100 \mathrm{yr}$, our understanding of ice cream science and how to use that science to control manufacturing practices to optimize product quality and manufacturing efficiency is still not complete. Some particular areas of interest might include the following.

One of the most critical aspects of ice cream quality during shelf life is coarsening of ice crystals, particu- larly in frost-free freezers where temperatures fluctuate on a regular basis. The use of stabilizers to reduce this coarsening is widespread, but our understanding of exactly how and why large molecular weight stabilizers inhibit recrystallization is still somewhat uncertain. Armed with a better scientific understanding of the phenomenon, food scientists may be able to design specific additives to target recrystallization. One example of that might be ice-structuring proteins, which interact with the ice crystal surface to strongly inhibit recrystallization (Regand and Goff, 2006). Although this possibility has been recognized since the 1990s, applications in commercial products are still limited.

Ice cream has long been considered an indulgent treat. Recently, food technologists have worked to improve the functional and nutritional quality of ice cream and frozen desserts. For example, frozen yogurt was developed around 1980 as a healthy alternative to ice cream. Numerous developments have taken place since then, including but not limited to fat reduction, sugar replacement, protein enhancement, and probiotic addition. Based on the current health trend, such efforts will continue in the future.

New developments in ice cream freezer technology will be likely in the future as freezers are better engineered to control the complex microstructures in ice cream. Current freezers are designed to form ice, create air bubbles, and destabilize fat globules in the short time that ice cream spends in the scraped surface freezer. A better understanding of how to optimize each of these structure developments will lead to more efficient freezer operations.

\section{REFERENCES}

Adleman, R., and R. W. Hartel. 2001. Lipid crystallization and its effect on the physical structure of ice cream. Pages 381-427 in Crystallization Processes in Fats and Lipid Systems. N. Garti and K. Sato, ed. Marcel Dekker, New York, NY.

Akalı, A. S., C. Karagözlü, and G. Ünal. 2008. Rheological properties of reduced-fat and low-fat ice cream containing whey protein isolate and inulin. Eur. Food Res. Technol. 227:889-895.

Akbari, M., M. H. Eskandari, M. Niakosari, and A. Bedeltavana. 2016. The effect of inulin on the physicochemical properties and sensory attributes of low-fat ice cream. Int. Dairy J. 57:52-55.

Alvarez, V. B., C. L. Wolters, Y. Vodovotz, and T. Ji. 2005. Physical properties of ice cream containing milk protein concentrates. J. Dairy Sci. 88:862-871.

Arbuckle, W. S. 1960. The microscopical examination of the texture and structure of ice cream. Ice Cream Trade J. 56:62.

Auld, G., C. J. Boushey, M. Ann Bock, C. Bruhn, K. Gabel, D. Gustafson, B. Holmes, S. Misner, R. Novotny, L. Peck, S. Pelican, D. Pond-Smith, and M. Read. 2002. Perspectives on intake of calcium-rich foods among Asian, Hispanic, and White preadolescent and adolescent females. J. Nutr. Educ. Behav. 34:242-251.

Baer, R. J., N. Krishnaswamy, and K. M. Kasperson. 1999. Effect of emulsifiers and food gum on nonfat ice cream. J. Dairy Sci. 82:1416-1424.

Balthazar, C. F., H. L. A. Silva, R. M. S. Celeguini, R. Santos, G. M. Pastore, C. A. C. Junior, M. Q. Freitas, L. C. Nogueira, M. C. 
Silva, and A. G. Cruz. 2015. Effect of galactooligosaccharide addition on the physical, optical, and sensory acceptance of vanilla ice cream. J. Dairy Sci. 98:4266-4272.

Berger, K. G. 1990. Ice cream. Pages 367-444 in Food Emulsions. 2nd ed. Marcel Dekker, New York, NY.

Berger, K. G., B. K. Bullimore, G. W. White, and W. B. Wright. 1972a. The structure of ice cream. Part 1. Dairy Industry 37:419 425 .

Berger, K. G., B. K. Bullimore, G. W. White, and W. B. Wright. 1972b. The structure of ice cream. Part 2. Dairy Industry 37:493497.

Bolliger, S., H. Wildmoser, H. D. Goff, and B. W. Tharp. 2000. Relationships between ice cream mix viscoelasticity and ice crystal growth in ice cream. Int. Dairy J. 19:791-797.

Bradley, R. L., Jr. 1984. Plotting freezing curves for frozen desserts. Dairy Record 84:86-87.

Buchanan, R. L., L. G. M. Gorris, M. M. Hayman, T. C. Jackson, and R. C. Whiting. 2017. A review of Listeria monocytogenes: An update on outbreaks, virulence, dose-response, ecology, and risk assessments. Food Contr. 75:1-13.

Buchheim, W., and E. Knoop. 1970. Distribution of butterfat and casein in completely and partly homogenized milk. Kieler Milchwirtschaftliche Forschungsberichte 22:323-327. (In German.).

Cadena, R. S., A. G. Cruz, J. A. Faria, and H. M. Bolini. 2012. Reduced fat and sugar vanilla ice creams: Sensory profiling and external preference mapping. J. Dairy Sci. 95:4842-4850.

Caldwell, K. B., H. D. Goff, and D. W. Stanley. 1992a. A low-temperature SEM study of ice cream. I. Techniques and general microstructure. Food Struct. 11:1-9.

Caldwell, K. B., H. D. Goff, and D. W. Stanley. 1992b. A low-temperature SEM study of ice cream. II. Influence of ingredients and process. Food Struct. 11:11-23.

Caulfield, W. J., and W. H. Martin. 1933. The use of vegetable stabilizers in ice cream. J. Dairy Sci. 16:265-270.

Cebula, D. J., and A. Hoddle. 2009. Chocolate and couvertures: Applications in ice cream. Pages 163-182 in Science and Technology of Enrobed and Filled Chocolate, Confectionery and Bakery Products. G. Talbot, ed. Woodhead, Cambridge, United Kingdom.

Chang, J.-L., R. T. Marshall, and H. Heymann. 1995. Casein micelles partially hydrolyzed by chymosin to modify the texture of lowfat ice cream. J. Dairy Sci. 78:2617-2623.

Chang, Y.-H., and R. W. Hartel. 2002a. Measurement of air cell distributions in dairy foams. Int. Dairy J. 12:463-472.

Chang, Y.-H., and R. W. Hartel. 2002b. Development of air cells in a batch ice cream freezer. J. Food Eng. 55:71-78.

Chang, Y.-H., and R. W. Hartel. 2002c. Stability of air cells during hardening and storage. J. Food Eng. 55:59-70.

Cole, W. C. 1932a. A microscopic study of ice cream structure. J. Dairy Sci. 15:421-433.

Cole, W. C. 1932b. Relation of temperature of ice cream to the distribution of certain of its components between the liquid and solid phases. J. Dairy Sci. 15:254-265.

Cole, W. C., and J. H. Boulware. 1940. Influence of some mix components upon the texture of ice cream. J. Dairy Sci. 23:149-157.

Cook, K. L. K., and R. W. Hartel. 2010. Mechanisms of ice formation in ice cream production. Comp. Rev. Food Sci. 9:213-222.

Cook, K. L. K., and R. W. Hartel. 2011. Effect of freezing temperature and warming rate on dendrite break-up when freezing ice cream mix. Int. Dairy J. 21:447-453.

Costa, F. F., J. V. Resende, L. R. Abreu, and H. D. Goff. 2008. Effect of calcium chloride addition on ice cream structure and quality. J. Dairy Sci. 91:2165-2174.

Daw, E., and R. W. Hartel. 2015. Fat destabilization and melt-down of ice creams with increased protein content. Int. Dairy J. 43:33-41.

Doan, F. J., and F. B. Baldwin. 1936. Observations on the freezing of milk and cream II. The destruction of the fat emulsion in frozen cream. J. Dairy Sci. 19:225-233.

Donhowe, D. P. 1993. Ice recrystallization in ice cream and ice milk. $\mathrm{PhD}$ Dissertation. University of Wisconsin-Madison.
Donhowe, D. P., R. W. Hartel, and R. L. Bradley Jr.. 1991. Ice crystallization processes during manufacture and storage of ice cream. J. Dairy Sci. 74:3334-3344.

Drewett, E. M., and R. W. Hartel. 2007. Ice crystallization in a scraped surface freezer. J. Food Eng. 78:1060-1066.

Dubey, U. K., and C. H. White. 1997. Ice cream shrinkage: A problem for the ice cream industry. J. Dairy Sci. 80:3439-3444.

Fabian, F. W., A. E. Hook, G. L. Nielsen, and G. J. Turney. 1942. A comparison of hot water, steam and chlorine for sanitizing ice cream freezers. J. Dairy Sci. 25:1-13.

Fay, A. C. 1933. A modification of the method for the direct microscopic examination of ice cream and other dairy products. J. Dairy Sci. 16:311-313.

Fisk, W. W. 1919. The Book of Ice Cream. MacMillan, New York, NY.

Flores, A. A., and H. D. Goff. 1999a. Ice crystal size distributions in dynamically frozen model solutions and ice cream as affected by stabilizers. J. Dairy Sci. 82:1399-1407.

Flores, A. A., and H. D. Goff. 1999b. Recrystallization in ice cream after constant and cycling temperature as affected by stabilizers. J. Dairy Sci. 82:1408-1415.

Frandsen, J. H., J. W. Rovner, and J. Luithly. 1919. Sugar saving substitutes in ice cream. J. Dairy Sci. 2:32-40.

Goff, H. D. 1997. Instability and partial coalescence in whippable dairy emulsions. J. Dairy Sci. 80:2620-2630.

Goff, H. D. 2008. 65 years of ice cream science. Int. Dairy J. 18:754758

Goff, H. D., K. B. Caldwell, D. W. Stanley, and T. J. Maurice. 1993. The influence of polysaccharides on the glass transition in frozen sucrose solutions and ice cream. J. Dairy Sci. 76:1268-1277.

Goff, H. D., and R. W. Hartel. 2013. Ice Cream. 7th ed. Springer, New York, NY

Goff, H. D., and W. K. Jordan. 1989. Action of emulsifiers in promoting fat destabilization during the manufacture of ice cream. J. Dairy Sci. 72:18-29.

Goff, H. D., J. E. Kinsella, and W. K. Jordan. 1989. Influence of various milk protein isolates on ice cream emulsion stability. J. Dairy Sci. $72: 385-397$

Guinard, J. X., C. Zoumas-Morse, L. Mori, B. Uatoni, D. Panyam, and A. Kilara. 1997. Sugar and fat effects on sensory properties of ice cream. J. Food Sci. 62:1087-1094.

Hagiwara, T., and R. W. Hartel. 1996. Effect of sweetener, stabilizer, and storage temperature on ice recrystallization in ice cream. J Dairy Sci. 79:735-744

Harper, E. K., and C. F. Shoemaker. 1983. Effect of locust bean gum and selected sweetening agents on ice recrystallization rates. J. Food Sci. 48:1801-1803.

Hartel, R. W. 1998. Mechanisms and kinetics of recrystallization in ice cream. Pages 287-319 in The Properties of Water in Foods: ISOPOW 6. D. S. Reid, ed. Blackie, London, United Kingdom.

Hening, J. C., and A. C. Dahlberg. 1929. The effects of certain salts on the physical properties of ice cream mixes. J. Dairy Sci. 12:129139

Hyvönen, L., M. Linna, H. Tuorila, and G. Dijksterhuis. 2003. Perception of melting and flavor release of ice cream containing different types and contents of fats. J. Dairy Sci. 86:1130-1138.

Javidi, F., S. M. A. Razavi, F. Behrouzian, and A. Alghooneh. 2016 The influence of basil seed gum, guar gum and their blend on the rheological, physical and sensory properties of low fat ice cream. Food Hydrocoll. 52:625-633.

Kalab, M. 1985. Microstructure of dairy foods. 2. Milk products based on fat. J. Dairy Sci. 68:3234-3248.

Kalab, M. 2010. The beauty of milk at high magnification. Infocus $18: 4-37$.

Keeney, P. G. 1958. The fat stability problem in ice cream. Ice Cream Rev. 42:26-28, 42-45.

Keeney, P. G., and D. V. Josephson. 1958. A measure of fat stability in ice cream. Ice Cream Trade J. 54:32-34, 36, 64, 98.

Keeney, P. G., and J. A. Maga. 1965. Factors affecting composition and yield of a foam fraction recovered from ice cream. J. Dairy Sci. 48:1591-1596. 
Keller, W. D., W. H. E. Reid, W. S. Arbuckle, and C. W. Decker. 1943. Microscopy of ice cream with polarized light. J. Dairy Sci. 26:683-688.

Kloser, J. J., and P. G. Keeney. 1959. A study of some variables that affect fat stability and dryness in ice cream. Ice Cream Trade J. $55: 26-28,30,32,86,88,92,121$.

Koxholt, M. M. R., B. Eisenmann, and J. Hinrichs. 2001. Effect of the fat globule sizes on the meltdown of ice cream. J. Dairy Sci. 84:31-37.

Leighton, A., A. Leviton, and O. E. Williams. 1934. The apparent viscosity of ice cream: I. The sagging beam method of measurement. II. Factors to be controlled. III. The effects of milkfat, gelatin and homogenization temperature. J. Dairy Sci. 17:639-650.

Leighton, A. A. 1927. On the calculation of freezing point of ice cream mix and of the quantities of ice separated during the freezing process. J. Dairy Sci. 10:300-308

Levin, M. A., K. J. Burrington, and R. W. Hartel. 2016. Whey protein phospholipid concentrate and delactosed permeate: Applications in caramel, ice cream, and cake. J. Dairy Sci. 99:6948-6960.

Levine, H., and L. Slade. 1986. A polymer physico-chemical approach to the study of starch hydrolysis products. Carbohydr. Polym. $6: 213-244$.

Levine, H., and L. Slade. 1988. Principles of cryostabilization technology from structure/function relationships of water-soluble food carbohydrates - A review. Cryo Lett. 9:21-63.

Levine, H., and L. Slade. 1992. Glass transitions in foods. Pages 83 221 in Physical Chemistry of Foods. H. Schwartzberg and R. W. Hartel, ed. Marcel Dekker, New York, NY.

Li, Z., R. Marshall, H. Heymann, and L. Fernando. 1997. Effect of milk fat content on flavor perception of vanilla ice cream. J. Dairy Sci. 80:3133-3141.

Mahdi, S. R., and R. L. Bradley Jr. 1969. Fat destabilization in frozen desserts containing low dextrose equivalent corn syrups. J. Dairy Sci. 52:1738-1741.

Méndez-Velasco, C., and H. D. Goff. 2012. Fat structure in ice cream A study on the types of fat interactions. Food Hydrocoll. 29:152159

Miller-Livney, T., and R. W. Hartel. 1997. Ice recrystallization in ice cream: Interactions between sweeteners and stabilizers. J. Dairy Sci. 80:447-456.

Moriano, M. E., and C. Alamprese. 2017. Honey, trehalose and erythritol as sucrose-alternative sweeteners for artisanal ice cream. A pilot study. Lebensm. Wiss. Technol. 75:329-334.

Mueller, W. S., and F. C. Button. 1929. The use of dehydrated egg products in the manufacture of ice cream. J. Dairy Sci. 12:320-335.

Muse, M. R., and R. W. Hartel. 2004. Ice cream structural elements that affect melting rate and hardness. J. Dairy Sci. 87:1-10.

Nickerson, T. A. 1954. Lactose crystallization in ice cream. I. Control of crystal size by seeding. J. Dairy Sci. 37:1099-1105.

Nickerson, T. A. 1956. Lactose crystallization in ice cream. II. Factors affecting rate and quantity. J. Dairy Sci. 39:1342-1350.

Nickerson, T. A. 1957. Lactose crystallization in ice cream. III. Mode of action of milk powder in preventing sandiness. J. Dairy Sci. 40:309-313.

Nickerson, T. A. 1962. Lactose crystallization in ice cream. IV. Factors responsible for reduced incidence of sandiness. J. Dairy Sci. $45: 354-359$.

Nickerson, T. A., and N. P. Tarussek. 1955. How to control shrinkage in ice cream. J. Dairy Sci. 38:1305-1306.

Parfitt, E. H., and C. L. Taylor. 1925. Effect of ingredients in the ice cream mix on its freezing point. J. Dairy Sci. 8:230-237.

Patel, M. R., R. J. Baer, and M. R. Acharya. 2006. Increasing the protein content of ice cream. J. Dairy Sci. 89:1400-1406.

Pelan, B. M. C., K. M. Watts, I. J. Campbell, and A. Lips. 1997. The stability of aerated milk protein emulsions in the presence of small molecule surfactants. J. Dairy Sci. 80:2631-2638.

Pinzer, B. R., A. Medebach, H. J. Limbach, C. Dubois, M. Stampanoni, and M. Schneebeli. 2012. 3S-characterization of three-phase systems using X-ray tomography: Tracking the microstructural evolution in ice cream. Soft Matter 8:4584-4594.
Prindiville, E. A., R. T. Marshall, and H. Heymann. 2000. Effect of milk fat, cocoa butter, and whey protein fat replacers on the sensory properties of lowfat and nonfat chocolate ice cream. J. Dairy Sci. 83:2216-2223.

Quinzio, J. 2009. Of Sugar and Snow: A History of Ice Cream Making. University of California Press, Berkeley.

Regand, A., and H. D. Goff. 2002. Effect of biopolymers on structure and ice recrystallization in dynamically frozen ice cream model systems. J. Dairy Sci. 85:2722-2732.

Regand, A., and H. D. Goff. 2003. Structure and ice recrystallization in frozen stabilized ice cream model systems. Food Hydrocoll. $17: 95-102$.

Regand, A., and H. D. Goff. 2006. Ice recrystallization inhibition in ice cream as affected by ice structuring proteins from winter wheat grass. J. Dairy Sci. 89:49-57.

Roland, A. M., L. G. Phillips, and K. J. Boor. 1999. Effects of fat replacers on the sensory properties, color, melting, and hardness of ice cream. J. Dairy Sci. 82:2094-2100.

Russell, A. B., P. E. Cheney, and S. D. Wantling. 1999. Influence of freezing conditions on ice crystallization in ice cream. J. Food Eng. 39:179-191.

Schmidt, K. A., and D. E. Smith. 1992. Milk reactivity of gum and milk protein solutions. J. Dairy Sci. 75:3290-3295.

Shama, F., and P. Sherman. 1966. The texture of ice cream. 2. Rheological properties of frozen ice cream. J. Food Sci. 31:699-706.

Sommer, H. S. 1932. The Theory and Practice of Ice Cream Making. Olsen, Milwaukee, WI

Specter, S. E., and C. S. Setser. 1994. Sensory and physical properties of a reduced-calorie frozen dessert system made with milk fat and sucrose substitutes. J. Dairy Sci. 77:708-717.

Thiel, A. E., R. W. Hartel, P. T. Spicer, and K. J. Hendrickson. 2016 Coalescence behavior of pure and natural fat droplets characterized via micromanipulation. J. Am. Oil Chem. Soc. 93:1467-1477.

Tong, P. S., W. K. Jordan, and G. Houghton. 1984. Response surface methodology to study fat destabilization and development of overrun in ice creams produced with polyunsaturated safflower oil and milk fat blends. J. Dairy Sci. 67:779-793.

Tracy, P. H., and C. Y. McCown. 1934. A study of factors related to the hardening of ice cream. J. Dairy Sci. 17:47-60.

Tremaine, A. J., E. M. Reid, C. E. Tyl, and T. C. Schoenfuss. 2014 Polymerization of lactose by twin-screw extrusion to produce indigestible oligosaccharides. Int. Dairy J. 36:74-81.

Trgo, C., M. Koxholt, and H. G. Kessler. 1999. Effect of freezing point and temperature regulating parameters on the initial ice crystal growth in ice cream. J. Dairy Sci. 82:460-465.

Walstra, P. 2003. Physical Chemistry of Foods. Marcel Dekker, New York, NY

Warren, M. M., and R. W. Hartel. 2014. Structural, compositional, and sensorial properties of United States commercial ice cream products. J. Food Sci. 79:E2005-E2013.

Whelan, A. P., A. Regand, C. Vega, J. P. Kerry, and H. D. Goff. 2008 Effect of trehalose on the glass transition and ice crystal growth in ice cream. Int. J. Food Sci. Technol. 43:510-516.

Whitaker, R. 1933. Some factors influencing the crystallization of lactose in ice cream. J. Dairy Sci. 16:177-202.

Wildmoser, H., J. Schweiwiller, and E. J. Windhab. 2004. Impact of disperse microstructure on rheology and quality aspects of ice cream. Lebensm. Wiss. Technol. 37:881-891.

Wildmoser, H., and E. J. Windhab. 2001. Impact of flow geometry and processing parameters on ultra low temperature ice cream extrusion (ULTICE) on ice cream microstructure. Eur. Dairy Magazine $13: 26-32$.

Williams, O. E., and P. N. Peter. 1930. A new form of lactose crystal found in sandy ice cream. J. Dairy Sci. 13:471-477.

Wright, K. E. 1930. The effect of initial cooling temperature on gelatin in the aging of the ice cream mix. J. Dairy Sci. 13:406-415.

Zhang, Z., and H. D. Goff. 2005. On fat destabilization and composition of the air interface in ice cream containing saturated and unsaturated monoglycerides. Int. Dairy J. 15:495-500. 


\section{APPENDIX}

Table A1. Milestones in the development of frozen dairy desserts

\begin{tabular}{|c|c|c|}
\hline Date & Milestone & Reference \\
\hline $1600 \mathrm{~s}$ & $\begin{array}{l}\text { The earliest form of ice cream, frozen ice, is developed in Italy based on brine } \\
\text { freezing. }\end{array}$ & \\
\hline 1878 & Mechanical refrigeration is developed. & Goff and Hartel, 2013 \\
\hline 1905 & Emery Thompson develops the gravity-fed batch ice cream freezer. & Goff and Hartel, 2013 \\
\hline $1920 \mathrm{~s}$ & Numerous frozen products (e.g., Eskimo Pie, Popsicle) are introduced. & \\
\hline 1925 & Freezing point depression is calculated. & Parfitt and Taylor, 1925; \\
\hline 1932 & Ice cream is evaluated microscopically. & Cole, $1932 a$ \\
\hline 1932 & $\begin{array}{l}\text { Brine freezers are still common, but direct expansion freezers begin to take } \\
\text { over manufacturing. }\end{array}$ & Sommer, 1932 \\
\hline 1938 & $\begin{array}{l}\text { The Federal Food, Drug, and Cosmetic Act instituting standards of identity is } \\
\text { passed. }\end{array}$ & \\
\hline $1950 \mathrm{~s}$ & Vegetable gums replace gelatin as a stabilizer. & \\
\hline $1970-1972$ & The first scanning electron microscope images of ice cream are produced. & Berger et al., $1972 a, b$ \\
\hline $1980 \mathrm{~s}$ & Extrusion processes are developed for the production of ice cream novelties. & \\
\hline 1981 & The first frozen yogurt is marketed. & \\
\hline Late 1980s & $\begin{array}{l}\text { A polymer science approach to frozen foods is based on glass transition } \\
\text { temperature. }\end{array}$ & $\begin{array}{l}\text { Levine and Slade, 1986, } \\
1988\end{array}$ \\
\hline 1988 & The flash-frozen Dippin' Dots snack is invented. & \\
\hline $2000 s$ & The low-temperature extrusion process for ice cream is developed. & $\begin{array}{l}\text { Wildmoser and Windhab, } \\
2001\end{array}$ \\
\hline
\end{tabular}

